\title{
Heat Storage and Release Tests of Heat Storage Material with Crystal Transformation
}

\author{
By Tsuyoshi TOTAnI,${ }^{1)}$ Takuya KUnI, ${ }^{2)}$ Toshifumi SATOH, ${ }^{1)}$ Takuya ISONO, ${ }^{1)}$ Masashi WAKITA ${ }^{1)}$ and Harunori NAGATA ${ }^{1)}$ \\ ${ }^{1)}$ Faculty of Engineering, Hokkaido University, Sapporo, Japan \\ ${ }^{2)}$ Graduate School of Engineering, Hokkaido University, Sapporo, Japan
}

(Received July 29th, 2015)

\begin{abstract}
Trans-1,4-polybutadiene has the attractive characteristic of heat storage by crystal transformation to overcome the difficulty of the thermal design of micro- and nano-satellites. The on-orbit test of the material has been conducted for obtaining the characteristics of heat storage and release in the space environment. The trans-1,4-polybutadiene of 5.5 grams was mounted on Hodoyoshi 4 satellite. The total heat capacity is 440 Joules. It has been confirmed from the on-orbit temperature data that trans-1,4-polybutadiene is able to store and release heat in space more than 1000 cycles. It is shown that the mounted trans-1,4-polybutadiene used the full of heat storage capacity.
\end{abstract}

Key Words: Heat Storage Material, Crystal Transformation, Heat Storage Test, Heat Release Test

\section{Nomenclature}

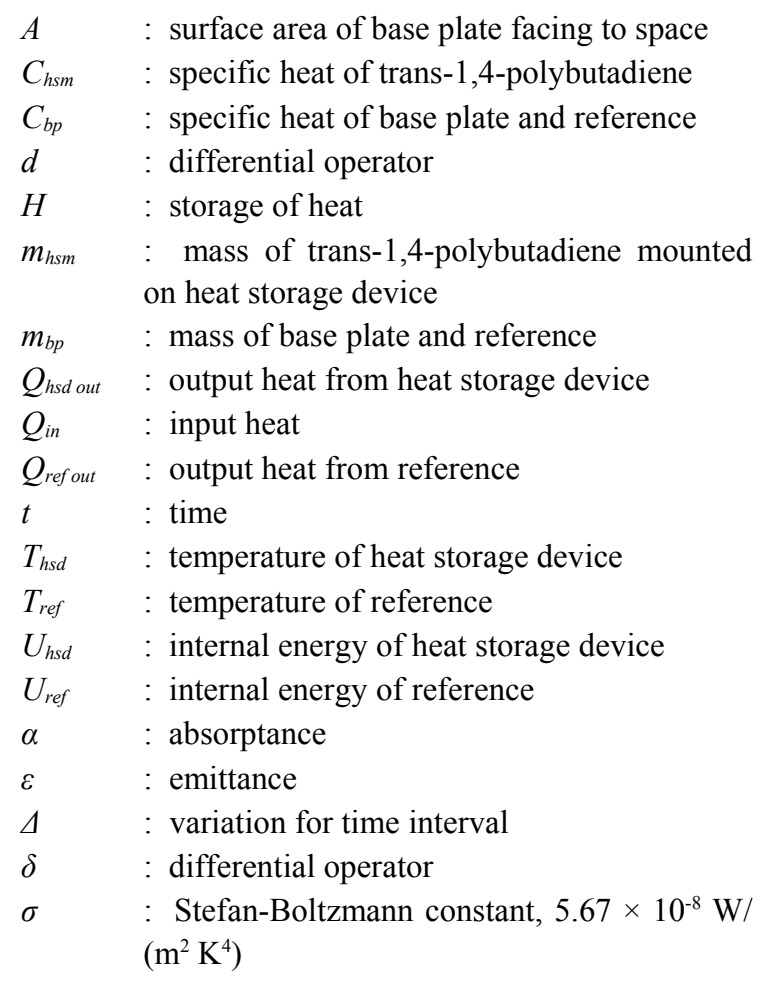

\section{Introduction}

Micro- and nano-satellites of not more than $100 \mathrm{~kg}$ in mass have been developed actively. It is expected that the microand nano-satellites realize a mission in a short period after the acceptance of order. It is essential to shorten the period of the design, the analysis, the fabrication, and the tests of microand nano-satellites.
The temperature control of micro- and nano-satellite is difficult. The temperature of micro- and nano-satellite changes easily because the heat capacity of micro- and nano-satellite is small. Heaters, thermal louvers, heat switches, phase-change materials, pumped fluid loops, thermoelectric coolers and heat pipes are well known as thermal control devices in satellites more than $100 \mathrm{~kg} .^{1)}$ The resource of electricity assigned to the temperature control subsystem is not enough to control the temperature of all components mounted in a micro- and nanosatellite actively. There is a severe restriction in mass of a micro- and nano-satellite in the case that the micro- and nanosatellite is launched by utilizing the piggyback system. It is difficult to mount traditional thermal louvers and pumped fluid loops from the viewpoint of the restrict in mass. The space for integrating a thermal control device is limited because many components are packed in the micro- and nanosatellite. The arrangement of heat pipe is quite difficult in micro- and nano-satellites. There are some components in micro- and nano-satellites which generate large amount of heat for a short time such as a radio transmitter. The radio transmitter used in micro- and nano-satellites generates several dozen watts for maximum 10 minutes to communicate between a ground station and the micro- and nano-satellite.

Ueno et al. are developing a MEMS-based small heat switch utilizing a near-field effect. ${ }^{2)}$ Hiroki et al. are developing a MEMS-based small thermal louver that works with an elastic force of a torsion bar and an electrostatic force. ${ }^{3)}$ We are interested in a thermal control device which stores heat temporarily at high heat dissipation and releases heat at low heat dissipation in order to manage the large amount of heat generated for a short time. The traditional heat storage materials store heat by the phase-change from solid to liquid. The liquid storage material needs a container that leads to the increase in mass. The liquid phase does not contact with a 
wall of the container in a micro-gravity condition in the case that the wetting characteristic between the heat storage material and the wall of the container is not good. We believe that the heat storage material not by phase-change but by crystal transformation has big attraction as a thermal control device for micro- and nano-satellites.

The final goal of this study is to simplify the thermal design by developing a thermal control device fitting to micro- and nano-satellites and to complete the thermal design of a microand nano-satellite in a short period less than 1 year. In this paper, the on-orbit test of the heat storage material with a crystal transformation is conducted for obtaining the characteristics of heat storage and release of the material in the space environment.

\section{Heat Storage Materials}

Table 1 shows heat storage materials which store heat at the temperature between 6 degree Celsius and 72 degree Celsius. ${ }^{4}$, 5) Most of the heat storage materials store heat by means of the phase change from solid to liquid. The liquid phase requires the attention to the wetting characteristic on the heat transfer surface in micro-gravity conditions. In the case that the wetting characteristic is bad, the liquid phase floats off a heat transfer surface in a micro-gravity condition and the heat transfer between the heat storage material and the heat transfer surface decreases extremely. Many liquid materials produce more outgas than solid materials at a same temperature. Trans1,4-polybutadiene is suitable for the heat storage material in the space use from viewpoints of the outgas and the contact between the heat storage material and the heat transfer surface. Trans-1,4-polybutadiene requires no container because trans-1,4-polybutadiene is solid at the heat storage by crystal transformation.

Table 1. Heat storage materials. ${ }^{1,5)}$

\begin{tabular}{|l|c|c|c|}
\hline Materials & $\begin{array}{c}\text { Temperature } \\
\text { of heat storage }\end{array}$ & $\begin{array}{c}\text { Amount of } \\
\text { heat storage }\end{array}$ & $\begin{array}{c}\text { Method of heat } \\
\text { storage }\end{array}$ \\
\hline $\begin{array}{l}\text { n-Tetradecane } \\
\left(\mathrm{C}_{14} \mathrm{H}_{30}\right)\end{array}$ & 6 deg. C. & $228 \mathrm{~kJ} / \mathrm{kg}$ & $\begin{array}{c}\text { Phase change from } \\
\text { sold to liquid }\end{array}$ \\
\hline $\begin{array}{l}\text { n-Hexadecane } \\
\left(\mathrm{C}_{16} \mathrm{H}_{34}\right)\end{array}$ & 17 deg. C. & $237 \mathrm{~kJ} / \mathrm{kg}$ & $\begin{array}{c}\text { Phase change from } \\
\text { sold to liquid }\end{array}$ \\
\hline $\begin{array}{l}\text { n-Octadecane } \\
\left(\mathrm{C}_{18} \mathrm{H}_{38}\right)\end{array}$ & 28 deg. C. & $244 \mathrm{~kJ} / \mathrm{kg}$ & $\begin{array}{c}\text { Phase change from } \\
\text { sold to liquid }\end{array}$ \\
\hline $\begin{array}{l}\mathrm{n}-\text { Eicosane } \\
\left(\mathrm{C}_{20} \mathrm{H}_{42}\right)\end{array}$ & 37 deg. C. & $246 \mathrm{~kJ} / \mathrm{kg}$ & $\begin{array}{c}\text { Phase change from } \\
\text { sold to liquid }\end{array}$ \\
\hline $\begin{array}{l}\mathrm{n}-\text { Octacosane } \\
\left(\mathrm{C}_{28} \mathrm{H}_{58}\right)\end{array}$ & $62 \mathrm{deg} . \mathrm{C}$. & $253 \mathrm{~kJ} / \mathrm{kg}$ & $\begin{array}{c}\text { Phase change from } \\
\text { sold to liquid }\end{array}$ \\
\hline $\begin{array}{l}\text { Trans-1,4- } \\
\text { polybutadiene }\end{array}$ & $72 \mathrm{deg} . \mathrm{C}$. & $112 \mathrm{~kJ} / \mathrm{kg}$ & $\begin{array}{c}\text { Crystal } \\
\text { transformation }\end{array}$ \\
\hline
\end{tabular}

\section{Trans-1,4-polybutadiene}

\subsection{Process of manufacture}

Trans-1,4-polybutadiene has been produced using the same way as a literature. ${ }^{5)}$ The recipe for making the trans-1,4polybutadiene is as follows: 1) Put toluene $37.5 \mathrm{~L}$ and

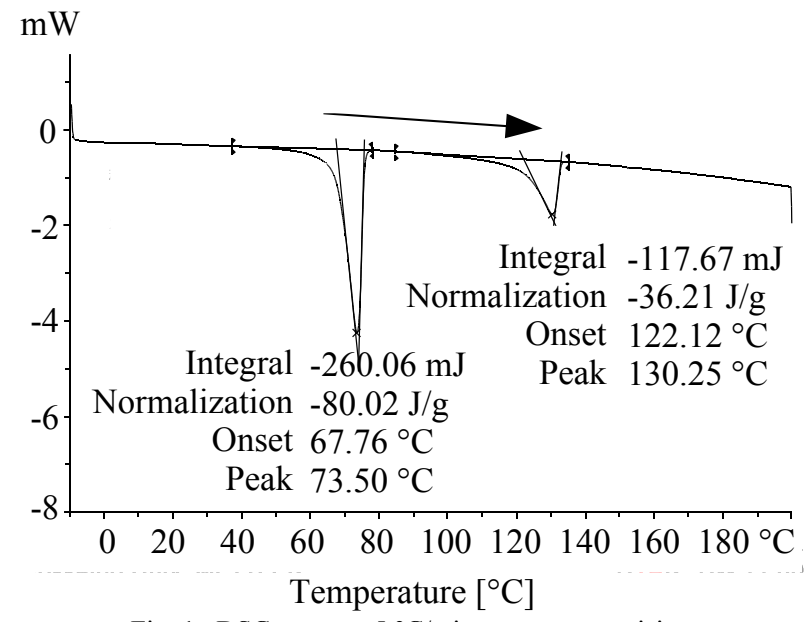

Fig. 1. DSC curve at $5{ }^{\circ} \mathrm{C} / \mathrm{min}$. temperature rising.

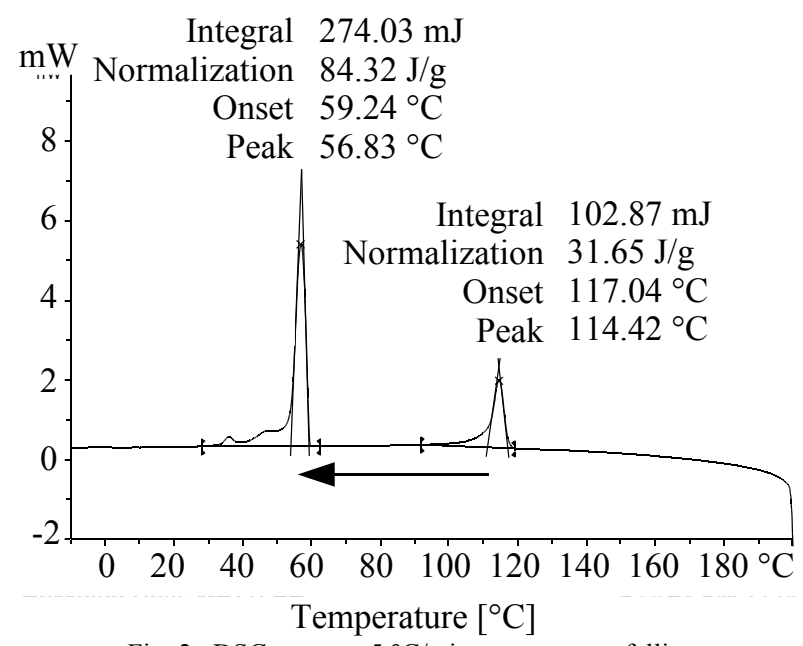

Fig. 2. DSC curve at $5{ }^{\circ} \mathrm{C} / \mathrm{min}$. temperature falling.

butadien $12.5 \mathrm{~L}$ in the autoclave substituted for nitrogen. 2) Put vanadium oxytrichloride $250 \mathrm{mmol}$ as a catalyst in the autoclave. Put diethylaluminum chloride $1250 \mathrm{mmol}$ as a promotor in the autoclave and start the polymerization. The polymerization is carried out in the nitrogen at -5 degree Celsius for 30 minutes. 3) Put twice volume of ethanol with respect to the polymerization solution in the autoclave, precipitate the polymer and filter the polymer. 4) After the filtering polymer is washed in ethanol, oxidation inhibitor Irganox $10763 \mathrm{wt} \%$ is mixed in the solution, the polymer is finally desiccated.

\subsection{Measurement of storage of heat}

The amount of heat storage of produced trans-1,4polybutadiene was measured using Differential Scanning Calorimeter (DSC), METTLER TOREDO DSC 1. The measurements are carried out after the temperature of trans1,4-polybutadiene rises from $25{ }^{\circ} \mathrm{C}$ to $200{ }^{\circ} \mathrm{C}$ under nitrogen atmosphere, the trans-1,4-polybutadiene is maintained at 200 ${ }^{\circ} \mathrm{C}$ for 10 minutes and melts perfectly, and the temperature is dropped from $200{ }^{\circ} \mathrm{C}$ to $25^{\circ} \mathrm{C}$. In measurements of storage of heat, the temperature rises from $-10{ }^{\circ} \mathrm{C}$ to $200{ }^{\circ} \mathrm{C}$ at a constant rate and is dropped from $200{ }^{\circ} \mathrm{C}$ to $-10^{\circ} \mathrm{C}$ at a constant rate.

Figure 1 shows the DSC curve at the temperature rise of $5{ }^{\circ} \mathrm{C}$ per minute and the amount of heat storage at the crystal 
transformation from a solid phase to the other solid phase and at the phase change from a liquid phase to a solid phase. The right endoergic reaction in the lower curve and the right exoerginc reaction in the higher curve means heat storage by the phase change from a solid phase to a liquid phase and heat release by the phase change from a liquid phase to a solid phase, respectively. It is clarified that the amount of heat storage is about $80 \mathrm{~J} / \mathrm{g}$ at the crystal transformation and $36 \mathrm{~J} / \mathrm{g}$ at the phase change. The obtained amount of heat storage at the crystal transformation corresponds to $71 \%$ of the amount of heat storage reported in a literature, ${ }^{5)} 112 \mathrm{~kJ} / \mathrm{kg}$.

Figure 2 shows the DSC curve at the temperature drop of 5 ${ }^{\circ} \mathrm{C}$ per minute and the amount of heat release at the crystal transformation from a solid phase to the other solid phase and at the phase change from a liquid phase to a solid phase. It is clarified that the amount of heat release is about $84 \mathrm{~J} / \mathrm{g}$ at the crystal transformation and about $32 \mathrm{~J} / \mathrm{g}$ at the phase change. The temperature at the peak of heat release is about $57{ }^{\circ} \mathrm{C}$ at the crystal transformation. It is clarified that the temperature at the peak of heat release is quite different from the temperature at the peak of heat storage.

Table 2 shows the transition temperature of the crystal transformation and the amount of endoergic or exoergic heat at some rates of temperature rise or temperature drop. The transition temperature shifts to the higher temperature as the higher rate of temperature rise and shifts to the lower temperature as the higher rate of temperature drop. It is known that these phenomena is a typical characteristic of DSC measurements. The difference of transition temperature between at the temperature rise and at the temperature drop is larger than the difference of transition temperature between the temperature rising or falling rates. It is suspected that the difference of transition temperature between at the temperature rise and at the temperature drop could be caused by the supercooling phenomena and superheating phenomena.

Table 2. Transition temperature and exoergic or endoergic heat.

\begin{tabular}{|c|c|c|}
\hline $\begin{array}{c}\text { Temperature rasing or } \\
\text { falling rate, deg.C/min. }\end{array}$ & $\begin{array}{c}\text { Transition } \\
\text { temperature, deg.C }\end{array}$ & $\begin{array}{c}\text { Exoergic or } \\
\text { endoergic heat, } \mathrm{J} / \mathrm{g}\end{array}$ \\
\hline+2 & 72.63 & -79.63 \\
\hline+5 & 73.50 & -80.02 \\
\hline+10 & 75.00 & -80.07 \\
\hline-2 & 58.00 & +87.57 \\
\hline-5 & 56.83 & +84.32 \\
\hline-10 & 54.83 & +83.36 \\
\hline
\end{tabular}

\section{Heat Storage Device with Trans-1,4-polybutadiene}

Figure 3 shows the heat storage device with trans-1,4polybutadiene. Table 3 indicates the specifications of the heat storage device. Four plates of trans-1,4-polybutadiene were bonded by adhesive material KONISHI MOS8 and Kapton tape NITTO TAPE P224 on a base plate. The size of a trans-

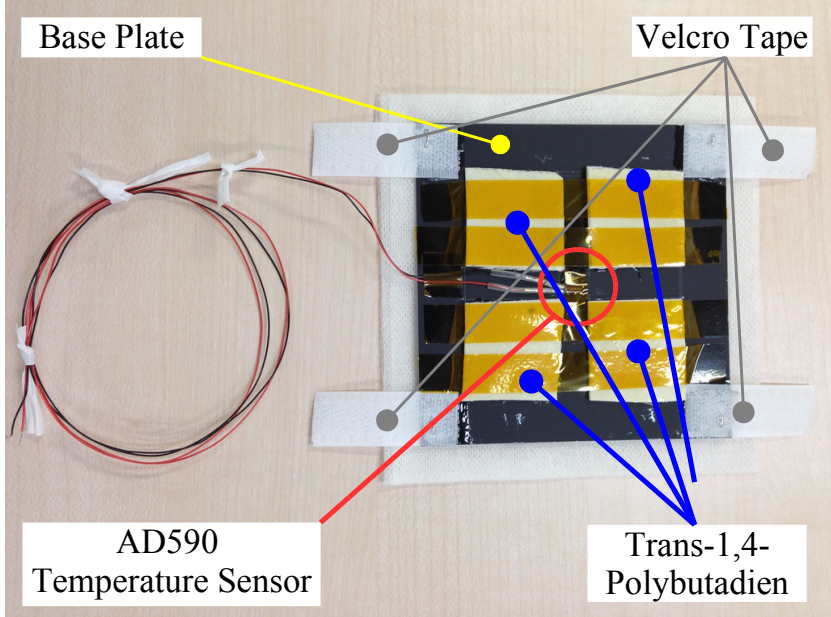

Fig. 3. Heat storage device.

1,4-polybutadiene plate is about $\mathrm{L} 30 \mathrm{~mm} \times \mathrm{W} 30 \mathrm{~mm} \times \mathrm{t} 1.5$ $\mathrm{mm}$. The total mass of trans-1,4-polybutadiene is $5.5 \mathrm{~g}$. The base plate is made of Aluminum Alloy 5052. The size of the base plate is $\mathrm{L} 100 \mathrm{~mm} \times \mathrm{W} 100 \mathrm{~mm} \times \mathrm{t} 0.5 \mathrm{~mm}$. The mass of the base plate is $13.4 \mathrm{~g}$. A black alumite was adopted as the

Table 3. Specifications of heat storage device.

\begin{tabular}{|l|l|}
\hline Items & Specifications \\
\hline Size of base plate & $\mathrm{L} 100 \times \mathrm{W} 100 \times \mathrm{t} 0.5 \mathrm{~mm}$ \\
\hline Material of base plate & Aluminum Alloy 5052 \\
\hline Mass of base plate & $13.4 \mathrm{~g}$ \\
\hline Specific heat of base plate & $900 \mathrm{~J} /(\mathrm{kg} \mathrm{K})$ \\
\hline Surface finishing on base plate & $\begin{array}{l}\text { Black Alumite }(\alpha=0.68, \varepsilon= \\
0.88)\end{array}$ \\
\hline $\begin{array}{l}\text { The size of trans-1,4- } \\
\text { polybutadiene plate }\end{array}$ & $\begin{array}{l}\text { About L } 30 \mathrm{~mm} \times \mathrm{W} 30 \mathrm{~mm} \times \\
\mathrm{t} 1.5 \mathrm{~mm}\end{array}$ \\
\hline $\begin{array}{l}\text { Total mass of trans-1,4- } \\
\text { polybutadiene }\end{array}$ & $5.5 \mathrm{~g}$ \\
\hline $\begin{array}{l}\text { Specific heat of trans-1,4- } \\
\text { polybutadiene }\end{array}$ & $1570 \mathrm{~J} /(\mathrm{kg} \mathrm{K})$ \\
\hline $\begin{array}{l}\text { Storage of heat of trans-1,4- } \\
\text { polybutadiene }\end{array}$ & About $80 \mathrm{~J} / \mathrm{g}$ \\
\hline $\begin{array}{l}\text { Conductivity of trans-1,4- } \\
\text { polybutadiene }\end{array}$ & $0.38 \mathrm{~W} /(\mathrm{m} \mathrm{K})$ \\
\hline $\begin{array}{l}\text { Temperature at the peak of } \\
\text { heat storage }\end{array}$ & $73.50 \mathrm{degree}$ Celsius \\
\hline $\begin{array}{l}\text { Melting point of trans-1,4- } \\
\text { polybutadiene }\end{array}$ & $130.25 \mathrm{degree}$ Celsius \\
\hline $\begin{array}{l}\text { Temperature at the peak of } \\
\text { heat release }\end{array}$ & $56.83 \mathrm{degree} \mathrm{Celsius}$ \\
\hline $\begin{array}{l}\text { Freezing point of trans- } 1,4- \\
\text { polybutadiene }\end{array}$ & 114.42 degree Celsius \\
\hline Adhesive material & KONISHI MOS8 \\
\hline Kapton tape & NITTO TAPE P224 \\
\hline $\begin{array}{l}\text { Temperature sensor } \\
\text { AD59miconductor thermometer }\end{array}$ \\
\hline Method to mount to satellite & Velcro tape \\
\hline
\end{tabular}


surface finish of the base plate. The solar absorption and the emission of the black alumite is 0.68 and 0.88 , respectively. Temperature sensor AD590 was adhered on the center of the base plate. This heat storage device was bonded on a MLI of Hodoyoshi 4 by Velcro tape.

Figure 4 and Table 4 show an image and the specifications of Hodoyoshi 4, respectively. The difference between the reference shown in Fig. 4 and the heat storage device is only trans-1,4-polybutadiene. The reference shown in Fig. 4 do not have trans-1,4-polybutadiene plates on the base plate. The reference is lighter than the heat storage device by 4 trans-1,4polybutadiene plates. The surface finish, the mass and the size of the base plate of the reference are same with those of the base plate of the heat storage device. The heat storage and the reference are mounted on MLI of the sun-pointing surface of Hodoyoshi 4. Hodoyoshi 4 was launched on June 20, 2014, JST. The orbit of Hodoyoshi 4 is an sun-synchronous orbit with the apogee of $635 \mathrm{~km}$ and the eccentricity of 0.0024 . The attitude of Hodoyoshi 4 is sun-pointing or Earth-pointing. Hodoyoshi 4 is a micro-satellite with the dimension of L 0.5 $\mathrm{m} \times \mathrm{W} 0.6 \mathrm{~m} \times \mathrm{H} 0.8 \mathrm{~m}$ and the mass of $63.7 \mathrm{~kg}$.

Table 4. Specifications of Hodoyhoshi-4 satellite.

\begin{tabular}{|c|c|}
\hline Items & Specifications \\
\hline Launch Date & June 20, 2014, JST \\
\hline Dimensions & $\mathrm{L} 0.5 \times \mathrm{W} 0.6 \times \mathrm{H} 0.8 \mathrm{~m}$ \\
\hline Mass & $63.7 \mathrm{~kg}$ \\
\hline Type of orbit & Sun-synchronous orbit \\
\hline Apogee & $635 \mathrm{~km}$ \\
\hline Eccentricity & 0.0024 \\
\hline Attitude & Sun-pointing or Earth-pointing \\
\hline$\beta$ angle & 22.5 degrees \\
\hline
\end{tabular}

\section{Results and Discussion}

\subsection{Results of on-orbit tests}

Figure 5 shows the temperature histories of the heat storage device and the reference, and the total generated power of solar array panel, SAP, in 6 orbits on July 4, 2014, JST. Hodoyoshi 4 flies in the shadow region of the Earth when the total power generation is 0 . After Hodoyoshi 4 goes out of the shadow region, the temperatures of the heat storage device and the reference rise rapidly. The temperature of the heat storage device is lower than that of the reference in the temperature range from 80 to 90 degree Celsius. After Hodoyoshi 4 enters in the shadow region, the temperatures of the heat storage device and the reference drop rapidly. The temperature of the heat storage device is higher than the reference in the temperature range from 10 to -10 degree Celsius.

\subsection{Amount of heat storage}

The temperature differences between the reference and the heat storage device are found in Fig. 5. The temperature

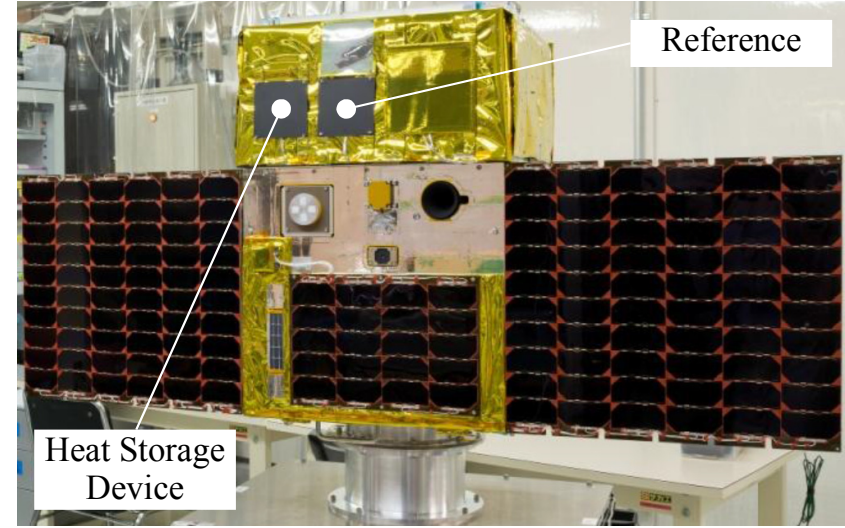

Fig. 4. Heat storage device and reference mounted on Hodoyoshi 4 satellite.

\section{¿-Reference SAP Total Power}

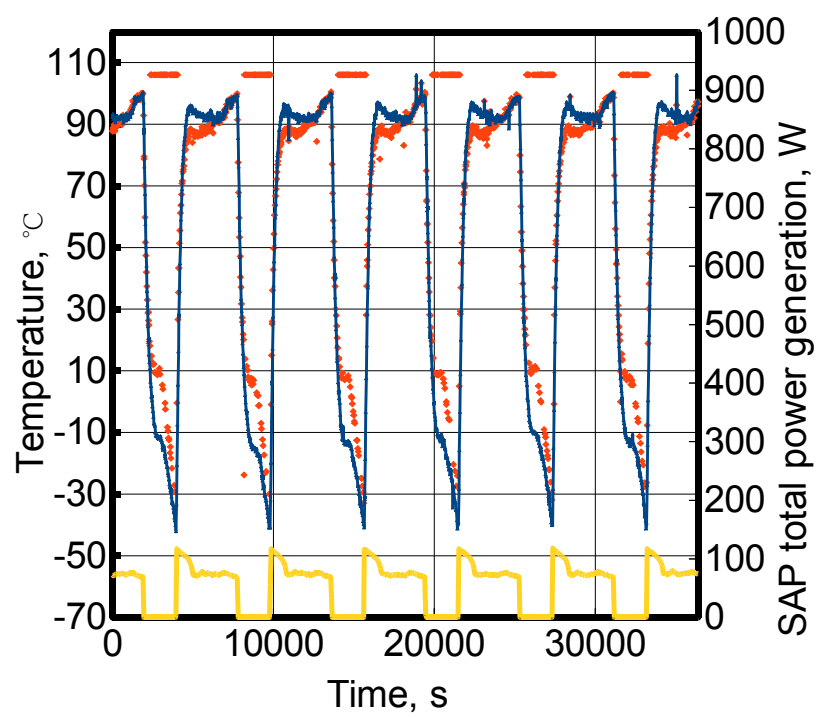

Fig. 5. Temperature histories of a heat storage device and a reference and the total generation power of SAP on July 4, 2014.

differences are generated by the effects of heat storage of trans-1,4-polybutadiene and the heat storage or release of the heat storage device. Applying the first law of thermodynamics to the heat storage device and the reference to get rid of the effect of thermal capacity, the following equations are obtained. The sensible heat and the storage of heat are assumed as the internal energy of heat storage device. The radiation is assumed as heat output from the heat storage device and the reference to space. The sensible heat is considered as the internal energy of the reference. It is assumed that the heat input from space to the heat storage device is same with that from space to the reference because the optical properties of both surface are same. The radiation is considered as the heat input. In the heat storage device,

$$
d U_{h s d}=\delta Q_{\text {in }}+\delta Q_{\text {hsd out }},
$$

where

$$
\begin{aligned}
& d U_{h s d}=\left(m_{h s m} C_{h s m}+m_{b p} C_{b p}\right) d T_{h s d}+\delta H, \\
& \delta Q_{h s d o u t}=\varepsilon \sigma T_{h s d}^{4} A d t .
\end{aligned}
$$




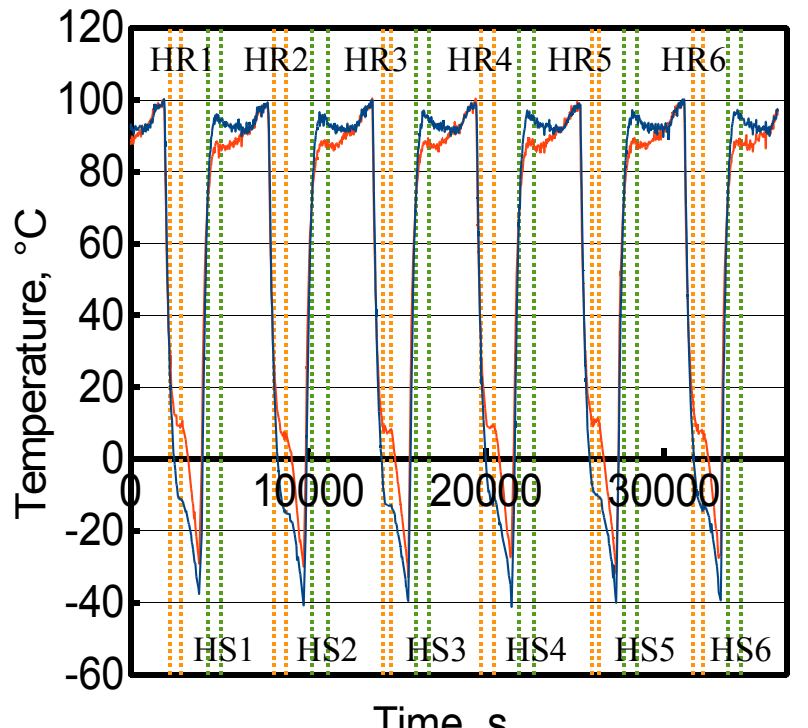

Fig. 6. Time spans of heat storage and heat release on temperature histories of a heat storage device and a reference on July 4, 2014.

In the reference,

$$
d U_{r e f}=\delta Q_{\text {in }}+\delta Q_{\text {ref out }},
$$

where

$$
\begin{aligned}
& d U_{r e f}=m_{b p} C_{b p} d T_{r e f}, \\
& \delta Q_{\text {ref out }}=\varepsilon \sigma T_{r e f}^{4} A d t .
\end{aligned}
$$

Solving these equations for $\delta H$ and integrating, the amount of heat storage or heat release for the time interval of the acquisition of data is expressed by

$$
\begin{gathered}
\Delta H=m_{b p} C_{b p}\left(\Delta T_{r e f}-\Delta T_{h s d}\right)-m_{h s m} C_{h s m} \Delta T_{h s d} \\
-\varepsilon \sigma\left(T_{h s d}^{4}-T_{r e f}^{4}\right) A \Delta t
\end{gathered}
$$

In the case that $\Delta H$ is positive, the heat storage device stores heat. In the case that $\Delta H$ is negative, the heat storage device releases heat. The mass of trans-1,4-polyburadiene mounted on the heat storage device of Hodoyoshi 4 is 5.5 grams. The amount of storage heat of trans-1,4,-polybutadiene is about 80 Joules per gram. The amount of heat storage is +440 Joules in the case that the all of trans-1,4-polybutadiene stores heat. The time spans when the sum of $\Delta H$ becomes about +440 Joules or -440 Joules are shown in Fig. 6. These time spans are obtained using the higher temperatures than the transition temperature in Table 2 at the temperature rise and the lower temperature than the transition temperature at the temperature drop. The heat storage device stores heat at time span between green broken lines and releases heat at the time spans between orange broken lines, respectively. This figure shows that the heat storage device used the full heat storage capacity.

Figure 7 shows the temperature histories of the heat storage device and the reference in 5 orbits on September 24, 2014, UST. The temperature histories in this figure have same trend as Fig. 5. There are 82 days from July 4 to September 24 . Hodoyoshi 4 orbits around 15 times per a day. These figures mean that the heat storage device could store and release heat 1230 times in space.

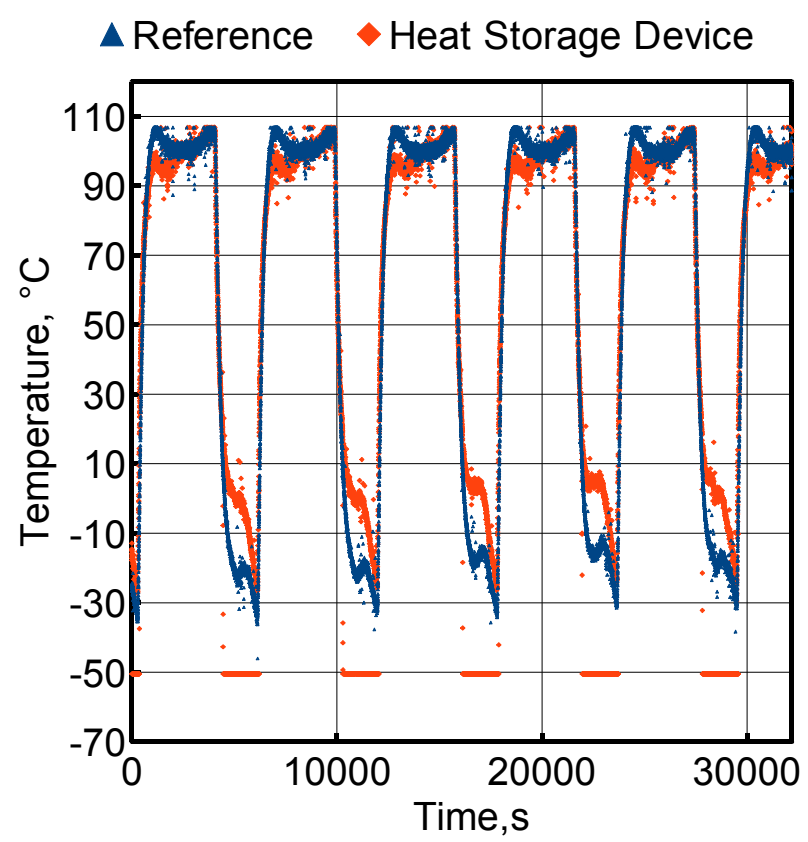

Fig. 7. Temperature histories of a heat storage device and a reference and the total generation power of SAP on September 24, 2014.

\subsection{Transition temperature at heat storage and heat release}

The transition temperatures at the temperature rises in onorbit tests in Fig. 7 are from 80 to 90 degree Celsius. These transition temperatures are higher than those measured in the ground tests shown in Table 2. The transition temperatures at the temperature drop in Fig. 7 are from 20 to 10 degree Celsius. These transition temperatures are lower than those measured in the ground tests shown in Table 2. Table 5 shows the temperature change rates at each heat storage and release numbers. The temperature change rate at a heat storage is the temperature change over the time between the bottom temperature and the start of heat storage. The temperature change rate at a heat release is the temperature change over the time between the peak temperature and the start of heat release. Temperature changes in on-orbit tests are faster than those in the ground tests. The faster temperature changes in on-orbit tests contribute the shifts to the higher transition temperatures at the heat storage and to the lower transition temperature at the heat release.

Table 5. Temperature change rate of reference in on-orbit experiments.

\begin{tabular}{|l|c|c|c|c|c|c|}
\hline $\begin{array}{l}\text { Heat storage } \\
\text { number }\end{array}$ & HS1 & HS2 & HS3 & HS4 & HS5 & HS6 \\
\hline $\begin{array}{l}\text { Temperature } \\
\text { change rate, } \\
{ }^{\circ} \mathrm{C} / \text { min. }\end{array}$ & +13.7 & +15.1 & +15.5 & +15.7 & +16.9 & +18.6 \\
\hline $\begin{array}{l}\text { Heat release } \\
\text { number }\end{array}$ & HR1 & HR2 & HR3 & HR4 & HR5 & HR6 \\
\hline $\begin{array}{l}\text { Temperature } \\
\text { change rate, } \\
{ }^{\circ} \text { C/min. }\end{array}$ & -14.8 & -13.5 & -11.4 & -15.8 & -10.8 & -13.2 \\
\hline
\end{tabular}


The thickness of the trans-1,4-polybutadiene plate in on-orbit tests was $1.5 \mathrm{~mm}$. The small piece of trans-1,4-polybutadiene used in DSC measurements in ground tests is as thin as 0.1 $\mathrm{mm}$. Heat transfers by conduction in the plate and the small piece of the trans-1,4-polybutadiene. The temperature difference between the surface adhered to the base plate and the opposite surface of the trans-1,4-polybutadiene plate is larger than that of the small piece used in DSC measurements. The temperature sensor was adhered to the base plate and does not measure the temperature of trans-1,4-polybutadiene plates directly. The temperature at the part storing heat in the trans1,4-polybutadiene plate could be lower at temperature rise and be higher at temperature drop than the temperature measured by the temperature sensor. The difference of thickness between the plate and the small piece of trans-1,4polybutadiene could generate the difference of transition temperature between on-obit and ground tests.

\section{Conclusion}

In order to simplify the thermal design and to shorten the development period of the thermal design of a micro- and nano-satellites, a thermal control device based on a heat storage material with a crystal transformation (i.e. trans-1,4polybutadiene) was developed and submitted to on-orbit testing in order to obtain the characteristics of heat storage and heat release of the material in space. The heat storage device with 5.5 grams trans-1,4,-polybutadiene was developed and was mounted on Hodoyoshi 4. It has been demonstrated that the heat storage device with trans-1,4-polybutadiene can store and release heat in space more than 1000 cycles. It has been confirmed that the heat storage device is able to use the full capacity of heat storage, $440 \mathrm{~J}$.

\section{Acknowledgments}

This research is granted by the Japan Society for the Promotion of Science (JSPS) through the "Funding Program for World-Leading Innovative $\mathrm{R} \& \mathrm{D}$ on Science and Technology (FIRST Program)," initiated by the Council for Science and Technology Policy (CSTP).

\section{References}

1) Gilmore, D. (ed.): Spacecraft Thermal Control Handbook, $2^{\text {nd }}$ ed., The Aerospace Corporation, E1 Segundo, 2002, pp.331-521.

2) Ueno, A. and Suzuki, Y.: MEMS-based Active Control of Thermal Radiation Using the Near-field Effect, Proceedings of 41st International Conference on Environmental Systems, AIAA, 2011, AIAA2011-5256.

3) Hiroki, K., Mita, M., Tachikawa, S. Taguchi, Y., and Nagasaka, Y.: Evaluating Emissivity Properties of MEMS Shutter Array for Spacecraft, Proceedings of Thermal Engineering Conference'13, The Japan Society of Mechanical Engineers, Tokyo, 2013, E132. (in Japanese)

4) Gilmore, D. (ed.): Spacecraft Thermal Control Handbook, $2^{\text {nd }}$ ed., The Aerospace Corporation, El Segundo, 2002, pp.373-403.

5) Ube Industries. LTD., Japan Patent, 4487455. 